\title{
Presencia de la Doctrina de Seguridad Nacional en la revista Memorial del Ejército de Chile, 1960-1973*
}

\author{
Presence of the National Security \\ Doctrine in the journal Memorial del Ejército de Chile, 1960-1973 \\ Germán Alburquerque \\ Instituto de Historia y Ciencias Sociales \\ Universidad de Valparaíso-Chile \\ german.alburquerque@gmail.com \\ Francisca Ossandón \\ Universidad de Valparaíso-Chile \\ francisca.ossandon@alumnos.uv.cl \\ Daniela Quiroga \\ Universidad de Valparaíso-Chile \\ daniela.quiroga@alumnos.uv.cl
}

\section{Resumen}

El artículo estudia la revista Memorial del Ejército de Chile entre los años 1960 y 1973, con el propósito de precisar la presencia y circulación de la Doctrina de Seguridad Nacional entre los militares chilenos antes del Golpe de Estado que derrocó a Salvador Allende. Para ello se emprende un análisis bibliométrico que cuantifica los artículos que adhieren o que son afines a la Doctrina de Seguridad Nacional. Al mismo tiempo, se rastrea la aparición de ideas desarrollistas y progresistas en la revista. Se pretende probar la hipótesis de que en la década de los sesenta la Seguridad Nacional alcanza ya una fuerza insoslayable, que anuncia un cambio definitivo de dirección en el ejército chileno.

Palabras clave: Doctrina de Seguridad Nacional, militares, desarrollismo, Memorial del Ejército, Chile.

\footnotetext{
*Este artículo es producto del Proyecto FONDECYT Regular Nº1190464 de la Agencia Nacional de Investigación, ANID, Chile. Se origina de la tesis de Licenciatura en Historia de Francisca Ossandón y Daniela Quiroga presentada en la Universidad de Valparaíso el año 2020.
} 


\begin{abstract}
The article studies the journal Memorial del Ejército de Chile between 1960 and 1973, in order to determine the presence and circulation of the National Security Doctrine among the Chilean military before the coup that overthrew Salvador Allende. For this, a bibliometric analysis is undertaken that quantifies the articles that adhere to or are related to the National Security Doctrine. At the same time, the presence in the journal of developmentalist and progressive ideas is tracked. It is intended to test the hypothesis that in the sixties national security already reaches an unavoidable force, which announces a definitive change of direction in the Chilean army.
\end{abstract}

Keywords: National Security Doctrine; military, developmentalism, Memorial del Ejército, Chile.

Recibido: 10 de mayo 2021 · Aceptado: 30 de junio 2021

\section{Introducción}

El objetivo de este artículo es esclarecer, a través de la revista Memorial del Ejército, el grado de penetración de la Doctrina de Seguridad Nacional (DSN) entre los militares chilenos en el periodo anterior al Golpe de Estado, es decir, entre los años 1960 y 1973. Es sabido que la dictadura militar del general Pinochet se sustentó ideológicamente en la DSN, pero no está tan claro cuándo la Doctrina fue asimilada por las fuerzas armadas del país. En el presente trabajo se intentará determinar esa penetración en el ejército chileno-quedando pendiente lo ocurrido en la marina y en la fuerza aérea- por medio de las páginas del órgano de expresión más representativo de la institución, el Memorial del Ejército de Chile. Por cierto, lo indagado no cubrirá la totalidad de los integrantes de esa rama de las fuerzas armadas ni proveerá una respuesta definitiva a la pregunta, pero entendemos que brindará una aproximación consistente.
Averiguar el momento y la profundidad con que la DSN se instaló entre las filas castrenses es relevante porque enriquece al menos dos discusiones que desde hace tiempo vienen preocupando a los especialistas. La primera de ellas, de alcance continental y no solo nacional, gira en torno a la autonomía de las fuerzas armadas en el escenario de Guerra Fría; la segunda enfoca el momento en que los militares chilenos adoptaron la DSN, más precisamente, si lo hicieron antes o después de 1973.

El primer debate involucra sobre todo a las dictaduras del Cono Sur -Argentina, Brasil, Chile, Uruguay, extendiéndose a la Bolivia de Hugo Bánzer-pero también a la acción de las fuerzas armadas en Centroamérica. La explicación que se impuso para este fenómeno asoció a los militares del continente con Estados Unidos: en la lógica bipolar de la Guerra Fría, desde Washington se les manipuló para asegurar la fidelidad de los distintos países del bloque occidental a su cruzada 
anticomunista. Según esta lectura, las fuerzas armadas latinoamericanas habrían seguido las directrices estadounidenses tras sucumbir ante sus poco disimuladas presiones. Pero esta visión encierra el riesgo de limitar la responsabilidad de los militares en la ejecución de las dictaduras y en la estela de terror que dejaron. Contra esta explicación se ha reaccionado desde la propia academia estadounidense.

Para Frederick Nunn (2000), la influencia de EE. UU. ha sido exagerada, ponderando, en cambio, una influencia europea no solo más antigua sino también mejor recibida (la ayuda estadounidense habría sido recibida con resignación). En la Guerra Fría, continúa Nunn, lo que se observa es solo un reforzamiento de unos roles que los militares conocían bien. Para el caso chileno, Nunn identifica un ethos en las fuerzas armadas que vuelve coherente la intervención de 1973 y el modo en que gobernaron después. Es en una tradición de participación política, que databa de comienzos del siglo, donde se hallan las pistas del Golpe y sería erróneo entender éste como una mera reacción al gobierno de Allende incentivada desde Norteamérica (Nunn, 2000: 25-26).

John Bawden, por su parte, profundiza esta visión destacando la capacidad de las fuerzas armadas latinoamericanas -“instituciones semiautónomas"-de crear sus propias ideas sobre seguridad nacional. Subraya que la influencia del Pentágono no erosionó las tradiciones intelectuales nacionales ni los sentimientos anticomunistas ni el profesionalismo de los militares del continente, todo lo cual existía desde antes de la hegemonía estadounidense (Bawden, 2012: 5-6). Sobre Chile, especifica que en el ejército hacia 1945 ya eran apreciables análisis geopolíticos maduros, formándose una tradición académica en el campo de la seguridad nacional que se fortaleció con los análisis que los militares chilenos hacían de conflictos internacionales tales como la Guerra de Vietnam u otras guerras de liberación. De esa manera anidaba en los cuarteles la convicción de que era un deber intervenir en política si el Estado se hallaba amenazado (Bawden, 2012: 20-21)[1]. Aunque sus argumentos pueden ser verdaderos, nos parece que siempre se ha reconocido que fue en Sudamérica donde se sistematizaron las ideas que componían la DSN, pero eso no quita que el entrenamiento y el adoctrinamiento de Estados Unidos haya sido decisivo en el curso de los hechos.

La segunda discusión, aquella que aborda la trayectoria y las etapas de la DSN en Chile, en general se divide en dos posiciones: para algunos especialistas solo desde el año 1973 la Doctrina se impuso entre los militares; para otros su huella es rastreable, al menos, hasta la década del sesenta. Quien mejor representa la primera postura es Jorge Tapia Valdés, autor de una de las primeras sistematizaciones sobre la DSN en América Latina, sosteniendo que ésta, aunque conocida, “jamás fue enseñada, divulgada ni aceptada en Chile" hasta 1973, prevaleciendo hasta entonces la "concepción liberal del profesionalismo militar" (Tapia, 1980: 123). Enfatiza la naturaleza foránea de la DSN, ajena a la historia del país y sin arraigo en la mayoría del personal de las fuerzas armadas (Tapia, 1980: 124).

Carlos Huneeus, en su vasto estudio sobre el gobierno de Pinochet, asegura que los militares 
no asumieron la DSN sino hasta después del derrocamiento de Allende (y en parte gracias a la influencia de sus pares brasileños) (Huneeus, 2016: 188). Confiesa incluso haber revisado el Memorial y no haber encontrado ningún artículo referido a la DSN en aquella década (Huneeus, 2016: 673). Más matizado es lo que postula Augusto Varas al puntualizar que los "incipientes desarrollos doctrinarios" de la seguridad nacional recién adquirieron relevancia a fines de los sesenta (Varas y Agüero, 1984: XVII), mitigando la orfandad doctrinaria imperante. Agrega que un proyecto político sustentado por la DSN afloró solo una vez que los militares estuvieron en el gobierno y debieron articularse con sectores civiles (Varas y Agüero, 1984: xlviii).

Detengámonos ahora en lo que plantea Verónica Valdivia, quien no solo detecta la presencia de la DSN en los años sesenta, sino que también hace dialogar esta tendencia con otra muy arraigada al interior de los cuarteles y que denomina ibañismo. Su tesis es que en esa década aún es apreciable la impronta del general Carlos Ibáñez del Campo, presidente de Chile en dos periodos pero que inició su vida política con la intervención militar del año 1924. El ibañismo, según la autora, consiste en un estatismo desarrollista de inspiración populista que cree en un gobierno fuerte y eficaz para modernizar la sociedad y permitir la integración de los grupos subalternos. Esta corriente, que subyació por décadas bajo la superficie de la prescindencia política, "no fue derribada del todo" por la aparición de la seguridad nacional; al contrario, la DSN "actuó sobre este basamento y no sobre una tabla rasa", llegando incluso a producirse una mixtura entre "los residuos del 'Ibañismo' y la Doctrina" (Valdivia, 2003: 18).

De todos modos, Valdivia reconoce una oficialidad muy heterogénea, al punto que quienes adhirieron y comenzaron a dar forma a la versión chilena de la DSN apenas alcanzaron una fuerza real en los setenta (Valdivia, 2003: 23), durante el gobierno de la Unidad Popular (aunque en las páginas del Memorial, durante los años de Allende, fue más visible la corriente ibañista, replegándose la línea anticomunista [Valdivia, 2003: 66]). La investigación de Valdivia se basa en la revisión de revistas militares -el Memorial y la Revista de la Fuerza Aérea-, decretando un empate en la cantidad de artículos alusivos al desarrollo y los dedicados a la Guerra Fría.

Situándose en una perspectiva cercana a la de Valdivia, Pietro Taviani percibe en los años cincuenta y sesenta dos corrientes al interior del ejército que no son excluyentes. La primera encuentra en la Doctrina la principal clave de lectura para el análisis de los hechos nacionales e internacionales; la segunda cree en el desarrollo y el progreso al calor de un nuevo acercamiento al mundo civil (Taviani, 2007: 67).

Este artículo pretende profundizar lo avanzado sobre todo por estos dos últimos trabajos. Mediante un enfoque cuantitativo y cualitativo, analiza la revista Memorial del Ejército de Chile con el fin de medir la presencia de la Doctrina de Seguridad Nacional entre los militares en el periodo previo al Golpe de 1973. Nos preguntamos por la cantidad de artículos que denotan adhesión a la seguridad nacional, así como por el número de artículos bajo 
orientación del desarrollismo popular. La hipótesis que manejamos sugiere que existe ya hacia la década del sesenta una presencia insoslayable de la seguridad nacional. Sin embargo, esta figuración se expresaría más bien como una sensibilidad de seguridad nacional-o nacional-securitista-y no tanto como la Doctrina de Seguridad Nacional propiamente tal, sistematizada y rígida.

Esto quiere decir que, a nuestro parecer, seguridad nacional constituye un concepto válido para aglutinar una serie de ideas, posiciones y actitudes frente a la realidad contemporánea nacional y mundial. En un segundo momento, tal conjunto, algo disperso, se sistematizó dando origen a lo que se conocerá como Doctrina de Seguridad Nacional. Esta la entendemos como la ideología seguida y esgrimida por las dictaduras militares del Cono Sur entre las décadas del sesenta y ochenta, y cuyos enunciados eje eran los siguientes: 1) desde una visión geopolítica, se establece a la nación como origen y destino de toda acción política; 2) de acuerdo a lo anterior, es deber del Estado fijar los objetivos nacionales que guiarán la conducción del gobierno; estos objetivos se corresponden con el "ser nacional", es decir, con cierta identidad tradicional (integridad territorial, cultura occidental, cristianismo, democracia); 3) la seguridad es decisiva para resguardar la nación y los objetivos nacionales y no se escatiman esfuerzos para mantenerla; 4) se asume la bipolaridad como el horizonte global donde se insertan las naciones latinoamericanas; 5) esta inserción define al comunismo como una amenaza directa y omnipresente, y es deber del Estado prepararse para laguerra revolucionaria que el comunismo prepara; 6) existen pues fronteras ideológicas internas que deben vigilarse tanto como las nacionales o externas; 7) dentro de los objetivos nacionales y en la lógica de robustecer la seguridad concurren la modernización y el desarrollo económico como pilares de la planificación estatal.

Se constatará que solo unos pocos artículos pueden calificarse como promotores o representantes de la Doctrina de Seguridad Nacional. En cambio, el número se multiplica al contar los artículos que ostentan una sensibilidad de seguridad nacional. En esta segunda categoría incluiremos artículos que: 1) asumen la pertenencia de Chile al bloque occidental; 2) adhieren a la defensa hemisférica en el contexto de Guerra Fría; 3) manifiestan interés o preocupación por las nuevas formas de la guerra, principalmente, la guerra contrarrevolucionaria, antisubversiva o especial; 4) formulan análisis desde la geopolítica o utilizan conceptos de esta disciplina; 5) se manifiestan en contra de la Unión Soviética o de gobiernos comunistas, o bien alertan sobre la propagación del comunismo; 6) utilizan un lenguaje cargado de conceptos caros a la seguridad nacional, como objetivos nacionales, frente interno, poder nacional, estrategia; 7) divulgan el valor de las operaciones de inteligencia o hacen un llamado a potenciarlas. Cabe mencionar que entre los temas e intereses anteriores se cuentan algunos que son propios de las preocupaciones naturales e históricas del mundo militar. Por ejemplo, es normal que un oficial escriba sobre la estrategia, las operaciones de inteligencia o las nuevas formas de la guerra. Por tanto, para declarar un artículo dentro de esta categoría, la de sensibilidad de seguridad 
nacional, un artículo deberá combinar al menos dos de esos enunciados.

En paralelo a estas dos variantes de la seguridad nacional, en la categoría desarrollismo popular se incluirán los artículos cuya preocupación fundamental sea el desarrollo socioeconómico del país, de América Latina o del Tercer Mundo, así como aquellos que manifiestan una línea política progresista. Como se precisó, el desarrollo es también un tema propio de la Doctrina de Seguridad Nacional, por lo tanto, la diferencia radicará en el énfasis y la perspectiva empleados. En ese sentido, en los escritos que se plantean desde la seguridad nacional el desarrollo es un asunto subordinado.

\section{Metodología}

A través de un estudio bibliométrico queremos medir y cotejar las corrientes que se expresaron en el Memorial en el periodo indicado. La revista funge, así, como puerta de entrada al pensamiento militar de la época, pero no representa el discurso oficial del ejército. Sus páginas publican artículos de autores chilenos y extranjeros, militares o civiles, y muchos de ellos llevan una leyenda advirtiendo que no interpretan la opinión oficial de la revista. Es obvio, en todo caso, que la mera selección de los materiales a publicar es indicadora, en alguna medida, de lo que la institución quiere expresar.

Hemos consultado la colección del Memorial disponible en la web. Lamentablemente no está completa. Para el periodo 1960-1973 se revisaron 59 números de los 80 publicados. Además del año 1961, del cual no contamos con ningún ejemplar, las carencias se concentran en el lapso 1970-1973, donde solo se revisó catorce. La revista contiene por logeneral una editorial que se refiere a asuntos militares sin adoptar posiciones polémicas. En seguida aparecen los artículos, sección principal de la publicación. Luego se incluyen notas, informaciones, obituarios, reportajes fotográficos, etc.

Contabilizamos 402 artículos para el periodo. No fue sencillo calificar como tales a los materiales, ya que hay colaboraciones en diversos formatos, existiendo, por ejemplo, artículos de una página, otros sin firma, u otros presentados como esquemas. También hay reimpresiones, transcripciones, reseñas históricas, notas biográficas, etc. Por todo eso el número de 402 puede ser rebatido, pero la variación no será sustancial. Otra dificultad fue catalogar los números especiales dedicados a libros o monografías. Cada uno de ellos fue contado como un solo artículo. Del número total de artículos se han excluido dosieres de historia de Chile o del ejército.

Se hizo un recuento estadístico de los artículos asociados a la Doctrina de Seguridad Nacional, de los situados dentro de lo que definimos como sensibilidad de Seguridad Nacional, y de los artículos desarrollistas populares, estableciendo, además, cantidad de autores civiles y militares, así como de chilenos y extranjeros. Luego se calculó el número de artículos totales de autores extranjeros y se les separó por nacionalidad. No siempre fue posible determinar la nacionalidad del autor, y en muchas ocasiones solo se pudo presumir. Lo anterior compone la parte cuantitativa de la metodología. Lo cualitativo opera al clasificar los artículos en las tres tendencias. Se explicarán 
en detalle los criterios empleados para cada una de ellas.

\section{Los artículos doctrinarios}

Ingresan aquí aquellos textos que adhieren a los postulados centrales de la Doctrina de Seguridad Nacional. La investigación dio con un total de diez artículos, lo que nos permite afirmar que la DSN tuvo presencia en el Memorial del Ejército de Chile en el periodo examinado (1960-1973) (ver Anexo 1). El primer artículo con estas características data de 1962. Esto no quiere decir que antes no haya habido ningún artículo que remitiera a la Doctrina. Por el contrario, ya en el texto citado de Augusto Varas y Felipe Agüero se mencionan varios trabajos que en los años cincuenta aludían a la seguridad nacional. Destacamos también el artículo "Nuestra Seguridad Nacional", de Guillermo López Larraín ( $\left.{ }^{\circ} 261,1954\right)$, que ponía en el centro de su exposición el concepto de seguridad nacional, aunque sin emplear el lenguaje característico de la Doctrina.

El primer texto suscrito a la DSN no es en rigor un artículo sino un libro. Era esta una práctica común, en el periodo estudiado, de la revista: la de destinar un número entero a un libro o a una monografía. Fue el caso de La conducción estratégica de una campaña y de la guerra, cuyo autor era nada menos que el teniente coronel Carlos Prats González, quien luego sería general y comandante en jefe del ejército, ministro del interior de Salvador Allende y acérrimo defensor del constitucionalismo militar, lo que entre otras cosas le costaría la vida tras sufrir un atentado en Buenos Aires en 1974.
No deja de ser paradójico, en consecuencia, que Prats marcara este hito. En verdad, el libro versaba sobre un tema estrictamente militar como lo eran las operaciones en un escenario bélico, y si bien en un capítulo se mencionaba la seguridad nacional, sería el anexo titulado "Política de Seguridad Nacional" el que mostraría las formulaciones típicas de la Doctrina. La redacción es tan esquemática que es dudoso que fuera realizada por la mano de Prats, pero no se indica ninguna otra procedencia. Hacemos hincapié, además, en que aquí la seguridad nacional se subordina al poder civil y está concebida en un contexto de guerra efectiva.

De los diez artículos, seis se concentran entre 1965 y 1969. Y será uno de 1966 la primera gran manifestación de la Doctrina en el Memorial. $\mathrm{Su}$ autor, a diferencia del anterior, tendría una participación directa en el gobierno de Pinochet. Se trata de Alejandro Medina Lois, director de la Escuela de Paracaidistas en los años setenta y luego rector delegado de la Universidad de Chile. En "Seguridad Nacional, un concepto que debe difundirse", Medina, junto con definir la palabra e ilustrar sus múltiples dimensiones, todo con el lenguaje habitual de la DSN, hace un llamado para que la Seguridad Nacional sea una preocupación transversal de la sociedad, desbordando por cierto el dominio castrense. Llega a proponer una cátedra universitaria sobre la materia, con el fin de que el mundo civil se haga cargo de un concepto tan determinante y actual.

Entrando en los años setenta, los artículos doctrinarios decaen de modo sustancial. Como se advirtió, la cantidad de ediciones que se consultó para los 
años 1970, 1971, 1972 y 1973 (hasta septiembre) se redujo a catorce (de un total de 21). Pero en esos catorce fascículos solo un artículo se ajustó a esta sección[2]. Veremos también que los artículos bajo la categoría sensibilidad nacional-securitista descendieron notablemente. No deja de ser profético, en todo caso, que aquel único artículo figurara en el número 373, de mayo-agosto de 1973, es decir justo antes de producirse el Golpe.

Su autor fue el mayor Juan Barriga, y su título, "Lo que debemos saber sobre seguridad y defensa nacional". Es un artículo dirigido a un público amplio que con un tono didáctico explica todo lo que implica la seguridad nacional para el país, ciñéndose a los postulados clásicos de la ideología, aunque sin exhibir una intencionalidad política ostensible. No es un llamado a un levantamiento militar, por el contrario, subraya que la seguridad es un asunto político de responsabilidad del gobierno, quedando la defensa a cargo de las fuerzas armadas. Y junto con ponderar el debido respeto a la democracia y a la constitución, se pronuncia sobre el valor determinante del desarrollo socioeconómico.

Una vez producido el Golpe de Estado, la DSN aparecerá con habitualidad en el Memorial, aunque ello no es materia de este artículo[3]. Además, en el gobierno de Pinochet adquiriría creciente centralidad, revelándose como su ideología rectora. El compromiso de los militares chilenos con la Doctrina fue tal que, entre otras cosas, se rebautizó la Academia de Defensa Nacional como Academia Superior de Seguridad Nacional (1974), de la que emanó la revista Seguridad Nacional (1976-1982).
Respecto al periodo que sí es objeto de nuestro examen, es claro que la DSN nollegó a corporizarse a cabalidad. Que apenas diez artículos sobre un universo de 402 (un 2,48 por ciento) [4] adhieran a la DSN es un índice de que ésta, si bien era conocida o, mejor dicho, intuida, no era concebida como un cuerpo de ideas capaz de aglutinar a las fuerzas armadas en torno a un proyecto común (ver Gráfico 1). Esos diez artículos son, de todos modos, una prueba fehaciente de que la Doctrina circulaba entre los militares chilenos, si bien no adoptaba, todavía, el acento beligerante develado por la práctica de las distintas dictaduras. Era, podría decirse, una Seguridad Nacional de guante blanco.

\section{Gráfico 1. Artículos doctrinarios}

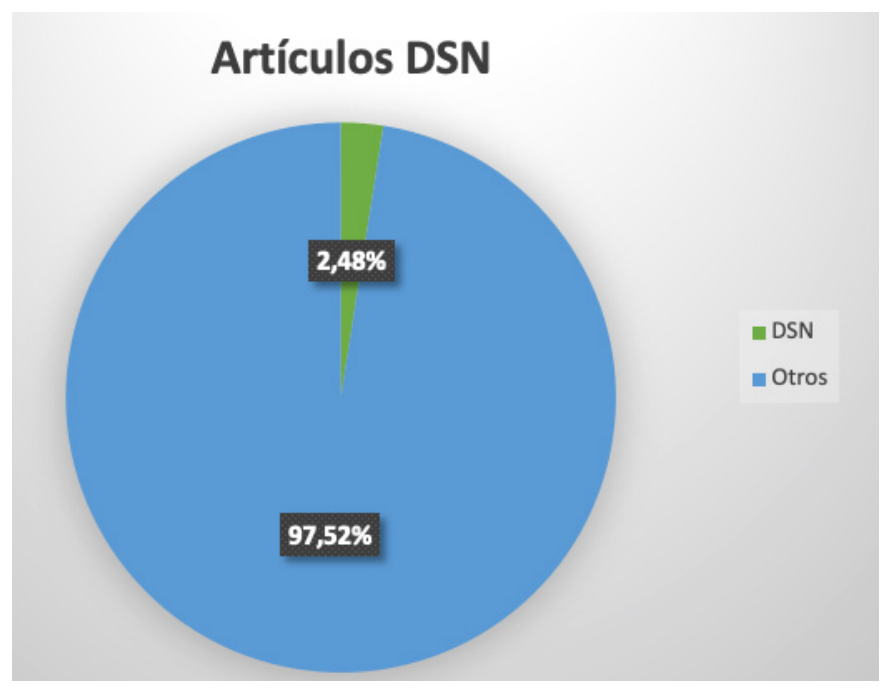

Elaboración propia. 


\section{Losartículosdesensibilidadnacional-securitista}

En esta categoría se han detectado 44 artículos, que corresponden al 10,94 por ciento del total, con un promedio de 3,38 artículos por año (ver Gráfico 2 y Anexo 2). 26 de esos artículos fueron escritos por autores extranjeros-más de la mitad-, con siete alemanes, siete estadounidenses y cinco españoles, entre otros.

\section{Gráfico 2: Artículos de sensibilidad nacional-securitista}

\section{Artículos Sensibilidad SN}

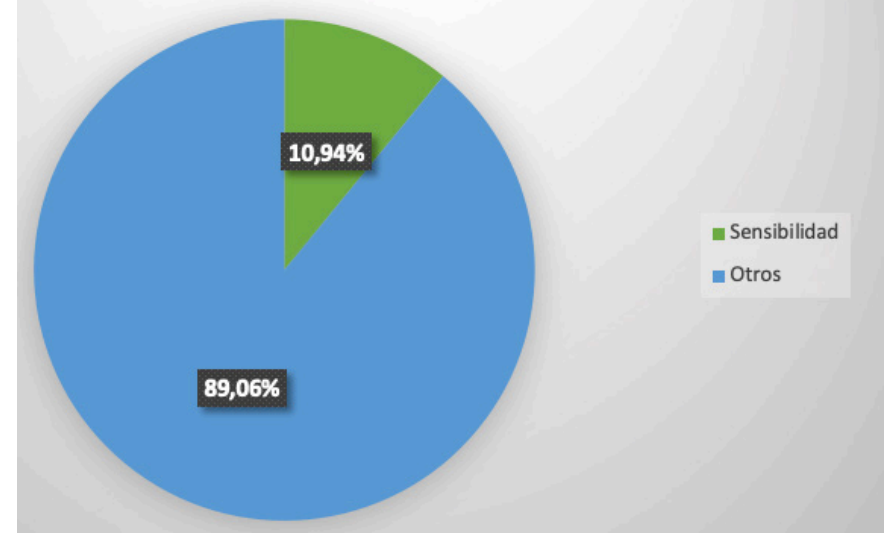

Elaboración propia.

Elgrueso de este conjunto lo constituyen artículos que analizan temas contingentes de la Guerra Fría y de las guerras de descolonización, sobre todo la de Vietnam. Si muestran una sensibilidad afín a la seguridad nacional no es, empero, solo por eso. Se incluyeron, por tanto, artículos que asumen una mirada hemisférica - es decir, un punto de vista occidental-y que en adición observan a la URSS o a otros países comunistas como una amenaza.

Otro nutrido grupo de artículos se refiere a las nuevas formas de la guerra, en especial la guerra de guerrilla. Es sabido que la DSN se articuló, en parte, a raíz del combate a la guerra irregular y como respuesta a la experiencia francesa en Indochina y Argelia y a la estadounidense en Vietnam. Pero, de nuevo, no es suficiente escribir acerca de la guerra de guerrilla para ingresar al círculo de la sensibilidad nacional-securitista: se trataba de un fenómeno real de alto interés para cualquier militar de cualquier lugar del mundo, afín o no a la seguridad nacional. Por ende, solo se ubican bajo esta etiqueta a los artículos que, refiriéndose a la guerrilla, lo hicieran en los términos de la seguridad nacional, o bien identificaran como amenaza alguna fuerza comunista, o bien recurrieran a autores influyentes en el ámbito de la seguridad nacional[5].

Un subconjunto, derivado del anterior, lo conforman artículos que se abocan a la realidad política del Asia sudoriental, incluyendo a China. La clave en este caso vuelve a ser la percepción de amenaza frente al comunismo. Se ha argumentado que el anticomunismo entre los militares chilenos es histórico y no privativo de la era de bipolaridad. En este caso, lo distinto es la aplicación del anticomunismo al análisis de un fenómeno concreto e inserto de lleno en la dinámica de la Guerra Fría.

Otro grupo de artículos, escritos por militares chilenos, se manifiesta sobre el sistema interamericano y la defensa hemisférica. Ello remite a los orígenes de la misma DSN y al modo cómo 
se propagó por el continente. Juzgamos, en consecuencia, que los artículos que no cuestionan y más bien se identifican con la alianza entre los ejércitos latinoamericanos y el de Estados Unidos, apoyando la unión interamericana en defensa de valores occidentales y en alerta ante el avance comunista, se sitúan dentro de la sensibilidad nacional-securitista.

Otro conjunto de artículos se asocia con la seguridad nacional también a través de Estados Unidos; son redactados por militares chilenos y comentan los avances de las fuerzas armadas norteamericanas, erigidas como arquetipo, agregando consideraciones específicas relacionadas con la seguridad nacional, como el valor de la estrategia y la inteligencia, o la adaptabilidad para enfrentar los nuevos desafíos bélicos.

En un número importante de artículos, oficiales chilenos abogan por la modernización tanto del Estado como de las fuerzas armadas, en aras de prepararse para enfrentar las amenazas que, según ellos, se cernían sobre el país. Se estimaba que, en materia de análisis estratégico, inteligencia, información, entrenamiento y equipamiento la nación no se hallaba todavía en forma ante eventuales focos de subversión. Tal argumentación se elaboraba con los conocidos términos implementados por la seguridad nacional, como poder nacional, enemigo interno o lucha antisubversiva.

Hemos también clasificado dentro de la sensibilidad de seguridad nacional artículos dedicados a la geopolítica o inspirados por la geopolítica. Esta disciplina científica es reconocida como una de las principales fuentes de las que bebieron los teóricos de la seguridad nacional en Europa,
Estados Unidos y también en Sudamérica. La idea típicamente geopolítica de que los Estados son seres vivos que requieren ciertas condiciones o transformaciones para su óptimo desenvolvimiento se halla en la raíz de la justificación del uso de la violencia para obtener ciertos fines. Por supuesto, la mera relación con la geopolítica no supone girar de inmediato en la órbita de la seguridad nacional. Es por esto, por lo que solo se han contabilizado aquellos artículos que desprenden de esa disciplina conclusiones políticas y prácticas aplicables a la contingencia.

El caso del general Augusto Pinochet ilustra el criterio empleado. Pinochet fue en los sesenta una autoridad en el terreno de la geopolítica nacional, publicando libros y artículos. El Memorial incluso reprodujo en uno de sus números especiales una obra suya. Pero solo se incluye aquí uno de sus trabajos, titulado "Significado militar de las relaciones espaciales", porque este articula, desde una lógica militar, un análisis de la geografía chilena y de sus ventajas y desventajas frente a menazas bélicas, todo con el propósito de maximizar el grado de seguridad tanto en el contexto vecinal como mundial[6].

A propósito de Pinochet, entre los autores chilenos que firman este conjunto figuran otros protagonistas de lo que después será la dictadura militar. Consignamos así los nombres de Julio Canessa Robert, futuro miembro de la junta de gobierno, de Agustín Toro Dávila, ministro de minería y rector delegado de la Universidad de Chile, y de Manuel Contreras Sepúlveda, director de la Dirección de Inteligencia Nacional, reconocido como el mayor criminal de la dictadura. 


\section{Los artículos desarrollistas-populares}

No fue fácil denominar esta corriente. Con la palabra desarrollista entendemos la preocupación especial por el desarrollo económico y por las condiciones sociales de amplios sectores de la población. Hacia los años sesenta, el desarrollismo estaba tan extendido que traspasaba derechas e izquierdas. Pero si todos eran desarrollistas tal etiqueta carecería de contenido. La clave está en el énfasis. Los artículos que aparecen en el Memorial y que se agruparon aquí, disertan acerca de cómo maximizar el desarrollo económico, poniendo en el centro de la discusión los recursos con que contaba la nación. Lo significativo es que se publican en una revista militar, consagrada, en principio, a temas militares. Es cierto que el Memorial estaba abierto a la inclusión de materiales no castrenses, siendo más o menos común la aparición de artículos científicos, por ejemplo, pero sin duda la revista enseñaba una intencionalidad al brindar espacio a textos de corte económico.

El segundo concepto de la categoría, popular, quiere reflejar la posición política de artículos firmados por militares chilenos afines al proceso progresista liderado por Salvador Allende, aunque sin explicitar apoyos partidistas o ideológicos, y que por lo mismo no son calificables de izquierdistas o socialistas. Popular, entonces, remite a la identificación con el pueblo y sus luchas.

Hemos identificado 28 artículos en esta categoría, lo que representa un 6,96 por ciento del total, con un promedio de 2,15 artículos anuales (ver Gráfico 3 y Anexo 3). Si se compara la cifra con el total de artículos relacionados a Seguridad Nacional,
54, parecería un número menor (ver Gráfico 4). A nuestro juicio es un número muy alto por lo que se explicaba recién: se trata una revista militar donde los tópicos relativos a seguridad nacional son naturales, esperables, a diferencia de los económicos. Aunque mantienen una presencia constante en el periodo, los artículos de esta sección experimentan un aumento en los últimos años, vale decir, durante la Unidad Popular.

Además, una nítida característica de esta línea es la figuración de autores civiles, responsables de al menos catorce colaboraciones (equivalentes al 50 por ciento). No conocemos bien cómo se gestaba la participación de autores civiles, varios de ellos de reconocida trayectoria académica; es probable que, por iniciativa de la revista, se publicasen determinados textos coincidentes o al menos no enfrentados con la línea editorial.

\section{Gráfico 3: Artículos desarrollistas populares.}

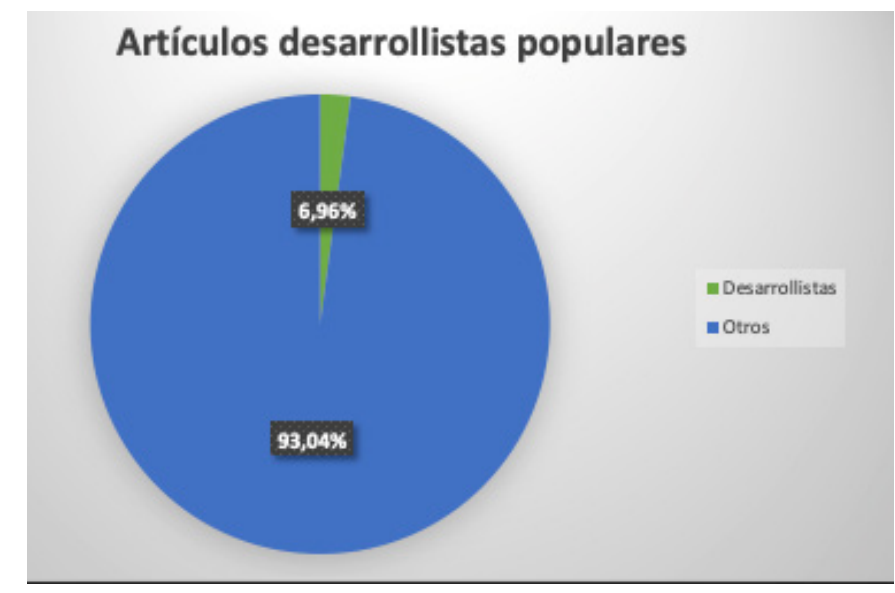

Elaboración propia. 


\section{Gráfico 4: Artículos totales.}

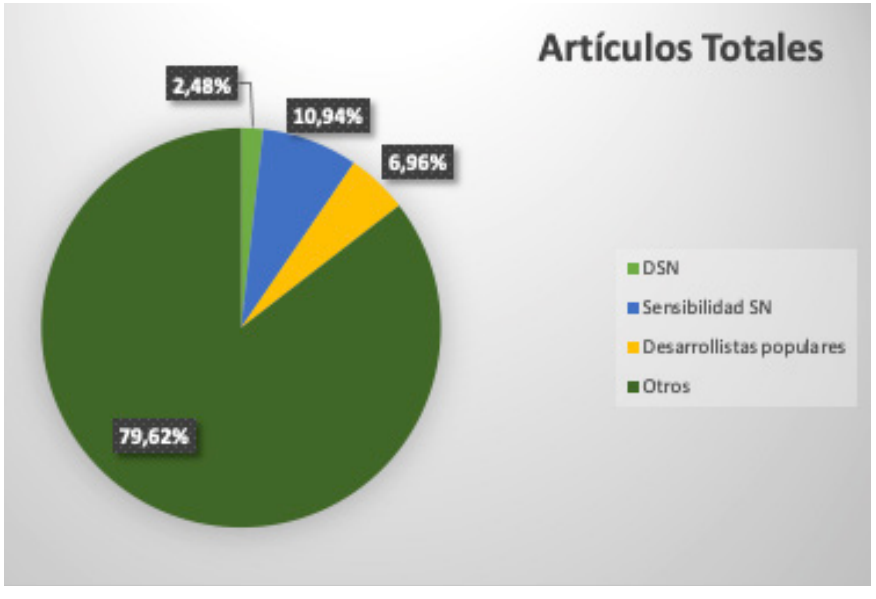

Elaboración propia.

Un primer subconjunto corresponde a textos que se abocan a las posibilidades de desarrollo y al aprovechamiento de los recursos humanos y naturales del país. Sería esta una posición compartida por la dirección de la revista dado que el medio adhirió, a través de una suerte de inserciones, de una o dos páginas y sin firma, tanto a la reforma agraria como a la nacionalización del cobre. Entre los militares el nacionalismo económico estaba extendido y de hecho pujó, durante los primeros años de la dictadura, contra el neoliberalismo para dirimir el modelo a seguir, con la consabida victoria de los Chicago boys.

En seguida destaca un pequeño grupo de cuatro artículos pertenecientes a autores extranjeros sobre las temáticas que hemos venido detallando y que llama la atención por la jerarquía de las firmas: un artículo corre por cuenta de Alberto Lleras Camargo, ex presidente de Colombia, titulado "El desarrollo de nuestro mundo", mientras que dos son firmados por el economista argentino Raúl Prébisch, a la sazón director de la Comisión Económica para América Latina, CEPAL, y uno de los teóricos más prominentes del desarrollo y de la dualidad centro-periferia (el primero de los artículos es recogido del conservador diario santiaguino El Mercurio).

Los artículos dedicados a la integración latinoamericana componen un compacto subconjunto, con un total de nueve textos entre 1967 y 1972. Con mayoría de autores civiles, analizan y valoran positivamente las tentativas integracionistas de la época, como el Pacto Andino y la Comisión Especial de Coordinación Latinoamericana (CECLA). Se incluyen aquí dos artículos divulgativos de la Conferencia de las Naciones Unidas para el Comercio y el Desarrollo, UNCTAD, el foro donde los países tercermundistas bregaban por un sistema económico mundial más justo, y que se vinculaba con los militares chilenos de forma singular. La tercera asamblea de la UNCTAD se realizó en Chile el año 1972, y el presidente Allende designó al general Orlando Urbina como vicepresidente de la comisión organizadora. Los artículos en mención hacen eco de ello.

Entre 1970 y 1972 aparecieron tres artículos que marcan un hito por su acentuado compromiso político con el proceso político nacional. El primero, "Las fuerzas armadas en el Tercer Mundo", del mayor Claudio López, explicaba los nuevos roles que los militares desempeñaban en los países subdesarrollados, que no eran idénticos a los desempeñados en los países ricos. En el Tercer Mundo se alzaba como un deber, por lo tanto, cumplir un papel político y social de 
transformación, sobre todo allí donde las élites civiles suponían un escollo.

En el mismo tono se expresaría el teniente coronel Hugo Moya en su breve ensayo "Participación, en teoría, de las fuerzas armadas en la política de los estados modernos". Es interesante notar que ambos artículos hacían alusiones a la seguridad nacional. El tercer artículo, firmado por cuatro uniformados, se titulaba "Tradición e innovación de la política exterior de Chile" y procedía de un trabajo universitario. En él, junto con elogiar la política exterior tercermundista y no alineada de la Unidad Popular, se precavía del riesgo de caer en una nueva dependencia, recomendando, en cambio, un camino intermedio entre el socialismo nacionalista y el pluralismo internacional.

Otros temas que captaron la atención del Memorial fueron la Alianza para el Progreso y el aporte de las fuerzas armadas al desarrollo económico del país (se repite un mismo artículo dos veces, aunque con distinto título).

\section{Autores extranjeros}

El propósito de esta sección es cuantificar la concurrencia de autores extranjeros en el Memorial, bajo la premisa, por una parte, de que la revista, al "importar" determinados artículos, enseña, en parte, su línea editorial; y por otra, de que la oficialidad del ejército entra en contacto, de esta manera, con determinadas ideas foráneas.

De los tres conjuntos revisados, los artículos provenientes de otras latitudes son muy significativos entre los de sensibilidad nacional-securitista, con 26 de 44 colaboraciones, mientras que en los grupos restantes la proporción es menor (4 de 28 entre los desarrollistas populares y 2 de 10 entre los doctrinarios). En esta sección específica no se clasifica la totalidad de los artículos, sino que solo se contabilizan y se separan por nacionalidad, dilucidándose los países potencialmente más influyentes sobre el ejército chileno.

A nivel regional las fuerzas armadas de Brasil, de Argentina, de Perú, de Chile y de otros países han recibido influencias europeas desde el siglo XIX. En Chile se produjo la prusianización del ejército y la impronta alemana fue de tal envergadura que, para algunos, como el ya citado Nunn (1975: 287; también Nunn, 2000:30), se extendió incluso hasta la dictadura de Pinochet. Como se apuntó, tras la Segunda Guerra Mundial la influencia de Estados Unidos se hizo incontrarrestable, canalizándose a través de tratados bilaterales, transferencia de armamento y tecnología, prácticas conjuntas y entrenamiento. Al momento de trazar los orígenes de la Doctrina de Seguridad Nacional también se ha señalado la influencia francesa (ver Gutiérrez, 2018; Ramos, 2019: 740; Loveman, 1999: 239) [7].

Esa historia de influencias se replica en el Memorial, dado que, de 402 artículos, 141 fueron escritos por extranjeros (incluyendo autores corporativos, como el ejército norteamericano, y autores no identificados: en ocasiones se menciona la revista desde donde fue traducido el artículo, pero no quién lo escribió), lo que representa un $35 \%$ (ver gráfico 5 ).

\section{Gráfico 5: Autores extranjeros.}




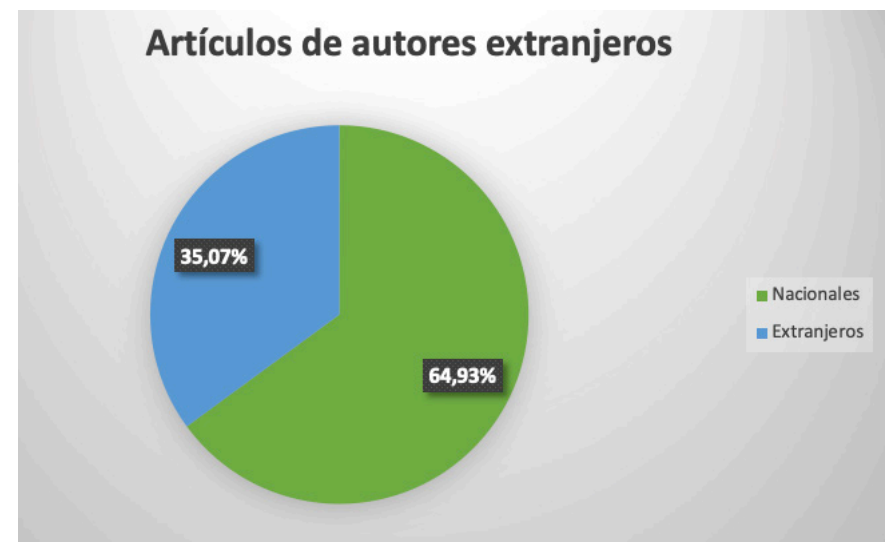

Elaboración propia.

El país con mayor presencia es Estados Unidos, seguido por Francia y Alemania Federal. Si a ellos se suman algunos británicos y ocho autores de los que no se pudo precisar la nacionalidad, aunque con certeza se trata de alemanes, franceses, estadounidenses o ingleses, se obtiene que los países más importantes del bloque occidental y de la OTAN constituyen una gran mayoría (ver Gráfico 6). Habría que sumar también a los autores de España, país bajo el gobierno militar de Francisco Franco, que no era miembro de la OTAN pero sí partidario de Estados Unidos en política exterior. Por tanto, el dominio de una sensibilidad, al menos, hemisférica, fue abrumador en las páginas del Memorial durante el periodo. Esto habla de una revista -y, por extensión, de una institución-abierta a los mensajes provenientes del exterior y presta a seguir modelos foráneos, quizá buscando esa orientación doctrinaria de la que, según algunos, se carecía en la coyuntura de los años sesenta y setenta.

\section{Gráfico 6: Autores extranjeros por nacionalidad.}

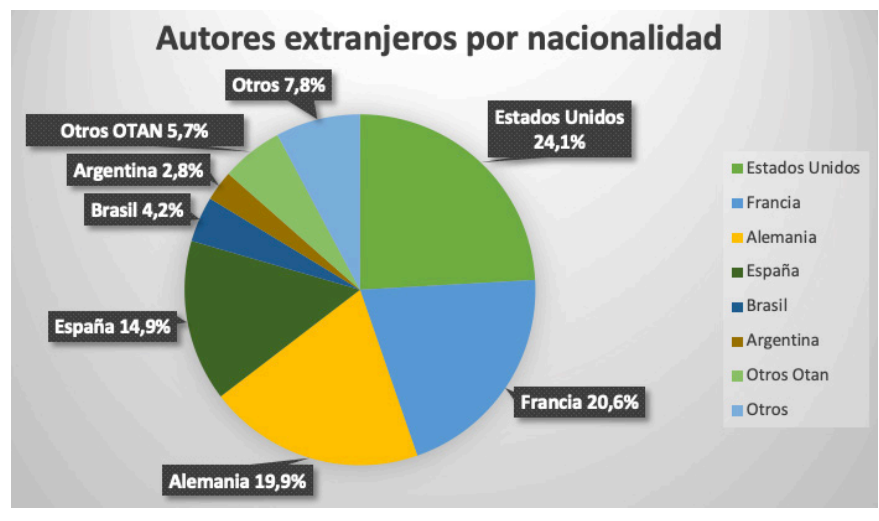

Elaboración propia.

\section{Conclusiones}

El tramo que examinamos del Memorial-de 1960 a 1973- ha sido objeto de análisis por otros observadores. Para Frederick Nunn, la revista se concentró en teoría geopolítica, materias profesionales, relaciones internacionales, exploración espacial e historia militar, abandonando temas políticos y sociales (Nunn, 1975: 285-286). El concepto de política que maneja Nunn aquí es evidentemente muy estrecho, reduciéndose más bien a deliberación política. San Francisco y Soto concuerdan en ello, puntualizando que, en el periodo 1958-1970, en la revista se advierten "tendencias y gérmenes de elaboración de temas políticos, sin caer en deliberación" (San Francisco y Soto, 2006: 112). Acotan que sus páginas atienden a la misión específica del ejército, a la importancia del hombre frente a nuevas tecnologías, a la afirmación de la soberanía territorial y al desarrollo del concepto de seguridad nacional (San Francisco y Soto, 2006: 80). Autores como Gutiérrez (2018: 110) y Ramos (2019) han subrayado cómo el Memorial introduce el estudio de las nuevas formas de la guerra. Este 
último asevera, asimismo, que la guerra nuclear y la geopolítica constituyeron, junto con la guerra no convencional, las preocupaciones primordiales de la revista.

Para nosotros resulta bastante claro que del Memorial se pueden hacer lecturas políticas directas. Es cierto que ocupan un espacio relevante temas histórico-militares, técnicos, gremiales y científicos, entre otros, pero los artículos clasificados en las tres categorías, en conjunto con otros de análisis internacional (en especial sobre conflictos bélicos) o de diversos asuntos contingentes son prueba de una revista profundamente interesada en la política, lo que se exacerba en los años setenta donde varias colaboraciones bordearon la deliberación, incluyendo algunas que no pudimos clasificar dada su ambigüedad y la dificultad de asignarle una postura política.

El estudio nos ha permitido determinar que la Seguridad Nacional, ya sea como sensibilidad o como Doctrina, se hallaba presente entre la oficialidad del ejército de Chile ya desde inicios de los años sesenta. De ello no deben extraerse conclusiones apresuradas. La seguridad nacional no era vista en esos tiempos como lo es ahora. Si aquí hemos compulsado la seguridad nacional con el desarrollismo popular ha sido con el propósito de distinguir mejor su representatividad, no porque fueran alternativas opuestas. Se ha dicho que al concebir la realidad militar de un país en términos de seguridad nacional se deja de lado el paradigma de la defensa; por lo tanto, la seguridad nacional debería competir con la defensa y no con el desarrollismo. Pero la verdad es que no es posible discernir una oposición, al menos en el periodo revisado, entre ambas concepciones, las que más bien se confunden y coexisten.

También hay algo de eso entre la seguridad nacional y el desarrollismo. Hubo artículos que combinaron elementos de una y de otro, lo que para nada fue un fenómeno exclusivo. En Perú, los militares que llegaron al poder el año 1968 interpretaron la seguridad nacional a su modo, pese a que compartían con sus símiles chilenos el paso por las mismas academias norteamericanas. Creían en una seguridad integral que incluía el desarrollo como pilar del progreso del país. En Ecuador, a partir de 1972 el gobierno de Guillermo Rodríguez Lara, al tiempo de imitar el progresismo de Velasco Alvarado en Lima, incorporó enunciados propios de la Doctrina en su discurso. Los militares chilenos, por su parte, no tenían motivos para renunciar al desarrollo reforzando la seguridad ni viceversa.

Tampoco la seguridad nacional se dejó ver en toda su magnitud. No leímos artículos que a partir de la seguridad nacional perfilaran el tipo de autoritarismo que se estaba fraguando en Brasily Argentina-lo que tampoco era muy transparente-ni el que se plasmaría en Chile desde 1973. La DSN, en sí, sienta las bases y justifica un ejercicio represivo y con visos totalitarios del poder, pero su contenido literal no es amenazante (por lo mismo es que ha sido esgrimida por gobiernos de derecha y de izquierda). La decena de artículos que guardan fidelidad a los principios de la Doctrina, como se expresó, no prefiguran lo que vendría después e incluso evidencian, quizá, cierta inocencia, como lo atestigua el hecho de que el primer difusor de esa ideología fuese Carlos Prats. 
Pero más allá de lo que significara seguridad nacional en los años sesenta y setenta, del destino que tendrían los autores que adherían con mayor o menor conciencia a ella, de las intenciones políticas o meramente militares que estos tuvieran, es indiscutible que en las páginas del Memorial se respiraba una atmósfera enrarecida, sobre todo, por la lógica de la Guerra Fría. El entorno-la realidad global-invadió la revista, e imaginamos que también a la oficialidad chilena. Nuestro trabajo midió el número de artículos asimilables con la seguridad nacional, pero no contempló un gran caudal de colaboraciones que analizaban la Guerra Fría en sus múltiples dimensiones. Tampoco contabilizó las notas e informaciones acerca de actividades militares relacionadas con Estados Unidos, como los viajes de oficiales a ese país o a sus academias.

El estudio de las influencias extranjeras mostró que las Fuerzas Armadas de Estados Unidos, Francia, Alemania Federal, España, Brasil y Argentina comparecen en la revista, exacerbando el clima bipolar y la identificación con el bloque occidental. Por todo lo anterior, nos parece que en la década de los sesenta es notorio que el ejército, en sus altas esferas, había adoptado una dirección inexorable. Ante tamaña hegemonía, los artículos desarrollistas se ven desde hoy como la postrera expresión de una tradición y cultura militar en extinción.

En cuanto a la autonomía del ejército chileno frente a poderes externos, nuestro trabajo solo puede insinuar algunos argumentos.
Se podría ensayar que mientras mayor sea la influencia que acusa un actor, menor sería su potencial de autonomía, y viceversa, mientras menor sea la influencia, mayor sería la autonomía. Que el Memorial denote una gran cantidad de colaboraciones provenientes del extranjero podría reflejar la disponibilidad del ejército para ponerse bajo el alero de Estados Unidos o del bloque occidental en general. Pero bien podría ser lo inverso, en el sentido de que, al estar en contacto y trabajar en comunión -como ocurría entre las fuerzas armadas de Chile y de Estados Unidos hacia esa época-, la figuración de artículos desde ese origen sería ya una consecuencia de la pérdida de autonomía. Tras todo lo expuesto en este estudio, solo se puede afirmar que, a través de su revista, la oficialidad chilena accedió a un clima de ideas fuertemente definido desde afuera, ya sea por la complacencia de los autores chilenos frente a la seguridad nacional, ya sea por los autores extranjeros que allí publicaron.

\section{Referencias citadas}

Barbosa, M. (2013): O pensamento político dos militares: uma análise sobre a Doutrina de Segurança Nacional através do Memorial del Ejército de Chile (1970-1974), Trabajo de conclusión de curso inédito, Universidade do Vale do Rio dos Sinos, São Leopoldo.

Barbosa, M. (2016): A “segunda independência” chilena - 11 de setembro de 1973: A construção do projeto refundacional através do Memorial del Ejército de Chile (1974-1990), Tesis de maestría inédita, Universidade do Vale do Rio dos Sinos, São Leopoldo.

Bawden, J. R. (2012): “Gazing Abroad, The Chilean Mi- 
litary's Reading of International Events: Implications for Doctrine, Ideology, and Behavior, 1945-1975", The Latin Americanist, 56(3), pp. 5-30.

Comblin, J. (1979): Dos ensayos sobre seguridad nacional, Santiago, Arzobispado de Santiago-Vicaría de la Solidaridad.

Gutiérrez, C. (2018): La contrasubversión como política. La doctrina de guerra revolucionaria francesa y su impacto en las FF.AA. de Chile y Argentina, Santiago, Lom.

Huneeus, C. (2016): El régimen de Pinochet, Santiago, Taurus.

Loveman, B. (1999): For la Patria: Politics and the Armed Forces in Latin America, Wilmington, SR Books.

Mendes, R. A. S. (2012): “Anticomunismo, Democraciae Geopolítica segundo Pinochet”, História Unisinos, 16(1), pp. 15-27, http://dx.doi.org/10.4013/htu.2012.161.02.

Nunn, F. (1975): “New Thoughts on Military Intervention in Latin American Politics: The Chilean Case, 1973", Journal of Latin American Studies, Cambridge, 7(2), pp. 271-304.

Nunn, F. (2000): “Foreign Influences on the South American Military: Professionalization and Politicization", en P. Silva, ed., The soldier and the state in South America:essays in civil-military relations, Nueva York, Palgrave, pp. 13-37.

Ramos, F. (2019): “La concepción de la Guerra a través de las revistas militares chilenas (1960-1970)", Vegueta. Anuario de la Facultad de Geografía e Historia, 19, pp. 733-757.

Rivas Nieto, P. (2008): Doctrina de Seguridad Nacional y regímenes militares en Iberoamérica, Alicante, Editorial Club Universitario.

San Francisco, A. y A. Soto (2006): Un siglo de pensamiento militar en Chile. El Memorial del Ejército 19062006, Santiago, Bicentenario.

Tapia Valdés, J. (1980): El Terrorismo de Estado. La Doctrina de la Seguridad Nacional en el Cono Sur, México DF, Revista Nueva Sociedad-Editorial Nueva imagen.

Taviani, P. (2007): “Entre participación y contrainsurgencia: los militares chilenos hacia el poder", en M. R. Stabili, ed., Entre historias y memorias. Los desafíos metodológicos del legado reciente de América Latina, Madrid, Ahila-Iberoamericana, pp. 63-90.

Valdivia, V. (2003): El golpe después del golpe. Leighus. Pinochet. Chile 1960-1980, Santiago, Lom.

Varas, A. y F. Agüero (1984): El proyecto político militar, Santiago, FLACSO.

\section{Anexos.}




\section{Anexo 1: Artículos Doctrina de Seguridad Nacional}

\begin{tabular}{|c|c|c|}
\hline Número/año & Título & $\begin{array}{l}\text { Autor (en negrita los autores } \\
\text { extranjeros) }\end{array}$ \\
\hline $\begin{array}{l}M^{\circ} 306-307 \\
(1962)\end{array}$ & La conducción estratégica de una campaña y de la guerra & Carlos Prats González \\
\hline $\mathrm{N}^{\mathrm{o}} 309(1962)$ & La guerra insurreccional & Carlos Neira [Meira] Mattos \\
\hline $\mathrm{N}^{\mathrm{o}} 314(1963)$ & Elementos del poder nacional & $\begin{array}{l}\text { Adaptación y traducción de } \\
\text { curso impartido en ejército } \\
\text { de EE. UU. por Hernán Vigil } \\
\text { Simpson }\end{array}$ \\
\hline $\mathrm{N}^{\mathrm{o}} 324(1965)$ & Introducción al estudio de la Información Estratégica (I. E.) & Julio Canessa Robert \\
\hline $\mathrm{N}^{\mathrm{o}} 327(1965)$ & Introducción al estudio de la Información Estratégica (I. E.) & Julio Canessa Robert \\
\hline $\mathrm{N}^{\mathrm{o}} 333(1966)$ & Seguridad nacional. Un concepto que debe difundirse & Alejandro Medina Lois \\
\hline No $337(1967)$ & La ciencia política y la seguridad nacional & Juan Barrientos Vidaurre \\
\hline $\mathrm{N}^{\mathrm{o}} 346(1968)$ & Administración de la seguridad nacional & Juan von Chrismar Escuti \\
\hline $\mathrm{N}^{\circ} 348(1969)$ & El frente interno en la estrategia general & Rafael Zavalla Carbó \\
\hline No $373(1973)$ & Lo que debemos saber sobre seguridad y defensa nacional & Juan D. Barriga M. \\
\hline
\end{tabular}

Anexo 2: Artículos de sensibilidad nacional-securitista 


\begin{tabular}{|c|c|c|}
\hline Número/año & Título & $\begin{array}{l}\text { Autor (en negrita los autores } \\
\text { extranjeros) }\end{array}$ \\
\hline$N^{o} 294(1960)$ & La Junta Interamericana de Defensa & Fernando Krumm U. \\
\hline$N^{o} 295(1960)$ & Política, estrategia y técnica & F.O. Miksche \\
\hline $\mathrm{N}^{\mathrm{o}} 295(1960)$ & La información estratégica & Guillermo López V. \\
\hline $\mathrm{N}^{\circ} 295(1960)$ & El ejército pentómico & $\begin{array}{l}\text { Película del Ejército de } \\
\text { EE. UU. adaptada y tra- } \\
\text { ducida por Ramón Rojas y } \\
\text { Fernando Fernández }\end{array}$ \\
\hline $\mathrm{N}^{\circ} 308$ (1962) & Como ganar la Guerra Fría & Richard M. Nixon \\
\hline $\mathrm{N}^{\mathrm{o}} 308(1962)$ & $\begin{array}{l}\text { El principio de la solidaridad ante la agresión en la aplicación } \\
\text { práctica en el sistema interamericano }\end{array}$ & Hernán Toledo Castillo \\
\hline $\mathrm{N}^{\mathrm{o}} 309(1962)$ & Misión en Brasil & Waldo Brücher Encina \\
\hline $\mathrm{N}^{\mathrm{o}} 309(1962)$ & La guerra de guerrillas & Enrique Blanche Northcote \\
\hline $\mathrm{N}^{\mathrm{o}} 309$ (1962) & $\begin{array}{l}\text { Las FF.AA. de Alemania Occidental, firme baluarte del } \\
\text { mundo de las democracias }\end{array}$ & Guillermo Gana Molina \\
\hline $\mathrm{N}^{\mathrm{o}} 310(1962)$ & Las guerrillas & Enrique Blanche N. \\
\hline $\mathrm{N}^{\circ} 311(1963)$ & Subversión-Propaganda-Rebelión & Sergio Fernández Rojas \\
\hline $\mathrm{N}^{\mathrm{o}} 312(1963)$ & Investigaciones americanas sobre la política y la estrategia & Jaques Vernant \\
\hline $\mathrm{N}^{\mathrm{o}} 312(1963)$ & Subversión-Propaganda-Rebelión (conclusión) & Sergio Fernández Rojas \\
\hline $\mathrm{N}^{\mathrm{o}} 313(1963)$ & ¿La guerra es aun un recurso de la política? & W. Ortmanns \\
\hline $\mathrm{N}^{\mathrm{o}} 317$ (1964) & $\begin{array}{l}\text { Nuevas ideas sobre estrategia en Estados Unidos de } \\
\text { Norteamérica }\end{array}$ & Stewart Alsop \\
\hline No 317 (1964) & Significado militar de las relaciones espaciales & Augusto Pinochet Ugarte \\
\hline No 318 (1964) & Pensamiento militar chino actual & José Hijar Ariño \\
\hline $\mathrm{N}^{\mathrm{o}} 318(1964)$ & Cuál es el poderío militar de la China comunista & Max Waibel \\
\hline No $320(1964)$ & Estudio y reflexiones en torno a la estrategia & Claude Delmas \\
\hline $\mathrm{N}^{\mathrm{o}} 325(1965)$ & El planeamiento de defensa del Occidente & Alexander L. Ratcliffe \\
\hline $\mathrm{N}^{\circ} 325$ (1965) & Sobre limitaciones y fines de la geopolítica & Henry Blumendahl \\
\hline $\mathrm{N}^{\mathrm{o}} 325(1965)$ & $\begin{array}{l}\text { Significado y posibilidades de la geopolítica europea y } \\
\text { especialmente alemana }\end{array}$ & Rolf Hinder \\
\hline $\mathrm{N}^{\circ} 326(1965)$ & Introducción al estudio de la Información Estratégica (I.E.)[] & Julio Canessa Robert \\
\hline No $327(1965)$ & Responsabilidad nacional de la defensa militar & Ulrich von Maiziere \\
\hline
\end{tabular}


N 331 (1966) El Estado y el servicio de informaciones. Su influencia en la conducción política del Estado

No 331 (1966) Estrategia en la Guerra de Vietnam

No 337 (1967) La guerra especial, forma de realización estratégica: instrucción y adiestramiento de fuerzas especiales

No 337 (1967) La seguridad del mundo occidental

No 339 (1967) La guerra revolucionaria. Gran cuestión de nuestro tiempo.

No 344 (1968) La defensa de Europa

No 344 (1968) Panorama político-estratégico del Asia sur-oriental

$\mathrm{N}^{\mathrm{o}} 344$ (1968) La guerra es política con derramamiento de sangre

$\mathrm{N}^{0} 346$ (1968) Las modernas formas de la guerra

$\mathrm{N}^{\mathrm{o}} 348$ (1969) Beaufre y la estrategia total

No 348 (1969) Antecedentes de la participación de EE.UU. de Norteamérica en Vietnam

No 350 (1969) Envolvimiento político-militar

$\mathrm{N}^{\mathrm{o}} 350$ (1969) Necesidad de patriotismo en nuestro tiempo

No 355 (1970) La limitación bélica y sus condicionantes políticos

No 355 (1970) Fundamentos de la estrategia

No 356 (1970) La evolución de la doctrina militar norteamericana después de 1945

N 356 (1970) Introducción al análisis de sistemas

$\mathrm{N}^{\mathrm{o}} 356$ (1970) La defensa operativa del territorio

No 356 (1970) Guerra de guerrillas urbanas

No 373 (1973) El poder exterior del Estado
Juan G. Hutt Guenther

Manuel Contreras Sepúlveda

Enrique Yávar Martin

Adolf Heusinger

Leandro Rubio García

Eugene Hinterhoff

Agustín Toro Dávila y Manuel

Contreras Sepúlveda

Gerhart Matthaus

Agustín Toro Dávila

Robert G. Krebs

Juan José Mela Toro

William R. Tracey

Leandro Rubio García

Leandro Rubio García

Klaus Goldschmidt

Peter Althaus

Traducción y adaptación del

Curso de Administración

de la Seguridad Nacional

impartido en EE. UU., por

Juan Von Chrismar E.

Juan Mateo Marcos

Philip D. Caine

Rafael Ortiz N. 


\section{Anexo 3: Artículos desarrollistas populares}

\begin{tabular}{|c|c|c|}
\hline $\begin{array}{l}\text { Número/ } \\
\text { Año }\end{array}$ & Título & $\begin{array}{l}\text { Autor (en negrita los autores } \\
\text { extranjeros) }\end{array}$ \\
\hline No 294 (1960) & $\begin{array}{l}\text { Nuestras industrias de telecomunicaciones y sus posibili- } \\
\text { dades hacia el campo de las FF.AA. }\end{array}$ & Renzo de Kartzow D. \\
\hline $\mathrm{N}^{\mathrm{o}} 296(1960)$ & Industrias forestales chilenas & Gonzalo Mendoza Aylwin \\
\hline $\mathrm{N}^{\circ} 297(1960)$ & Recursos energéticos de Chile & Edmundo González \\
\hline $\mathrm{N}^{\mathrm{o}} 310(1962)$ & $\begin{array}{l}\text { La situación económica y social del gremio de los pesca- } \\
\text { dores en Chile }\end{array}$ & Gonzalo Mendoza Aylwin \\
\hline $\mathrm{N}^{\mathrm{o}} 311(1963)$ & La Alianza para el Progreso & Emilio González Uriarte \\
\hline $\mathrm{N}^{\mathrm{o}} 312(1963)$ & La crisis estructural de América Latina & Raúl Prébisch \\
\hline $\mathrm{N}^{\mathrm{o}} 312(1963)$ & Los problemas del crecimiento económico de las naciones & Juan Carlos Godard \\
\hline $\mathrm{N}^{\mathrm{o}} 315(1963)$ & Contribución económica de las fuerzas armadas & René Gonzalez Rojas \\
\hline $\mathrm{N}^{\mathrm{o}} 316(1963)$ & Planificación, desarrollo y democracia & Raúl Prébisch \\
\hline $\mathrm{N}^{\circ} 319(1964)$ & Algo sobre la Alianza para el Progreso & C.F.A.N. \\
\hline No $322(1964)$ & $\begin{array}{l}\text { La reforma agraria y el crecimiento demográfico de América } \\
\text { Latina }\end{array}$ & Pedro Barbosa López \\
\hline No $322(1964)$ & Aspectos económicos de la provincia de Tarapacá & Guillermo Peña Freeman \\
\hline $\mathrm{N}^{\circ} 324(1965)$ & El desarrollo de nuestro mundo & Alberto Lleras Camargo \\
\hline $\mathrm{N}^{\mathrm{o}} 325(1965)$ & Distribución del ingreso y moderación social & Enrique Lackington \\
\hline No $333(1966)$ & Contribución de las FF. AA. al desarrollo económico & Rene González Rojas \\
\hline $\mathrm{N}^{\mathrm{o}} 339(1967)$ & La política internacional del actual gobierno de Chile & Jorge Mendoza Bahamonde \\
\hline No $339(1967)$ & Comunidad nacional e integración latinoamericana & Raimundo Barros Charlin \\
\hline $\mathrm{N}^{\circ} 344(1968)$ & El mercado común subregional & Leopoldo Durán Valdes \\
\hline $\mathrm{N}^{\circ} 344(1968)$ & La integración económica: una meta para el desarrollo & Pedro Howard Fuenzalida \\
\hline No 348 (1969) & $\begin{array}{l}\text { La integración de América futura y el proceso del poder } \\
\text { mundial }\end{array}$ & Horacio H. Godoy \\
\hline No 355 (1970) & $\begin{array}{l}\text { El sistema latinoamericano, la CECLA y el Nacionalismo } \\
\text { Continental }\end{array}$ & $\begin{array}{l}\text { Ministerio de Relaciones } \\
\text { Exteriores }\end{array}$ \\
\hline $\mathrm{N}^{\mathrm{o}} 356(1970)$ & Las fuerzas armadas en el Tercer Mundo & Claudio López Silva \\
\hline No $361(1971)$ & $\begin{array}{l}\text { Cambio y continuidad: el Pacto Andino en la historia } \\
\text { contemporánea }\end{array}$ & Claudio Véliz \\
\hline $\mathrm{N}^{\mathrm{o}} 363(1971)$ & América Latina en 1970 & Felipe Herrera Lane \\
\hline $\mathrm{N}^{\mathrm{o}} 364(1971)$ & La UNCTAD. & Raul Videla Medina \\
\hline
\end{tabular}




\begin{tabular}{|l|l|l|}
\hline$N^{\circ} 367$ (1972) & Tradición e innovación de la política exterior de Chile & $\begin{array}{l}\text { Efraín Jaña, Jaime Fuenzalida, } \\
\text { Jorge Stolze C., Lander } \\
\text { Uriarte B. }\end{array}$ \\
\hline $\mathrm{N}^{\mathrm{o}} 367(1972)$ & Un hogar chileno para la humanidad & $\begin{array}{l}\text { Entrevista de Simon Stancie } \\
\text { L. a Orlando Urbina }\end{array}$ \\
\hline $\mathrm{N}^{\mathrm{o}} 369(1972)$ & $\begin{array}{l}\text { Participación, en teoría, de las fuerzas armadas en la política } \\
\text { de los estados modernos }\end{array}$ & Hugo Moya V. \\
\hline
\end{tabular}




\section{Notas}

[1] Bawden reclama que el Informe Rettig sobre las muertes y la desaparición de personas durante la dictadura de Pinochet asigna un papel a Estados Unidos por la instrucción en contrainsurgencia prestada a los militares del continente, pero que no menciona la escuela geopolítica del ejército chileno (Bawden, 2012: 20-21).

[2] Para notar la diferencia, entre 1960 y 1969 apareció un artículo doctrinario cada cinco números; entre el 70 y el 73, uno cada catorce números.

[3] Ver Barbosa (2016) o San Francisco y Soto (2006).

[4] Diez artículos en los trece años revisados dan un promedio de 0,76 artículo por cada doce meses.

[5] Elaboramos esta lista de autores "clásicos" de la Doctrina de Seguridad Nacional, tras cruzar datos extraídos de distintos libros (Comblin 1979; Tapia, 1980; Rivas Nieto, 2008): Hans Morgenthau, Henry Kissinger, Rudolf Kjellen, Gaston Bouthoul, André Beaufre, Roger Trinquier, Robert McNamara, Erich Ludendorff, Halford John Mackinder y Karl Haushofer.

[6] Ricardo Mendes, también con el ánimo de rastrear los orígenes de la DSN en Chile, estudia la obra de Pinochet Ensayo sobre un estudio preliminar de una geopolítica de Chile (1965), concluyendo que allí ya se anuncia una lectura de derecha de la ideología, con elementos como el anticomunismo, la noción de democracia protegida y la geopolítica asociada a una predeterminada vocación nacional (Mendes, 2012: 26).
[7] Enfocando solo el tema de las nuevas concepciones de la guerra y en especial de la guerra contrasubversiva, Ramos ha destacado aportes desde Francia, Alemania y España, y ha explicado que en la revista la presencia estadounidense, a nivel teórico, fue más bien "indirecta y complementaria”, canalizándose, en cambio, a nivel “táctico operacional” (Ramos, 2019: 740).

[8] Este estudio se publicó por partes a lo largo de varios números. Algunas de esas partes coinciden con lo definido como DSN, y otras se adecuan a lo que se definió como sensibilidad SN. 